\title{
Quantitative Computed Tomography Measurement of Tracheal Cross-Sectional Areas in Relapsing Polychondritis: Correlations with Spirometric Values
}

\author{
Ayano Usuba $^{a}$ Tsuneo Yamashiro $^{b, d}$ Hiroshi Handa ${ }^{a}$ Shin Matsuoka ${ }^{b}$ \\ Yoshihisa Yamano $^{c}$ Masamichi Mineshita ${ }^{a}$ Teruomi Miyazawa ${ }^{a}$ \\ ${ }^{a}$ Division of Respiratory Medicine, Department of Internal Medicine, ${ }^{\mathrm{b}}$ Department of Radiology, and ${ }^{\mathrm{c}}$ Department \\ of Rare Diseases Research, Institute of Medical Science, St. Marianna University School of Medicine, Kawasaki, and \\ ${ }^{\mathrm{d}}$ Department of Radiology, University of the Ryukyus, Nishihara, Japan
}

\section{Key Words}

Relapsing polychondritis · Computed tomography ·

Trachea $\cdot$ Spirometry

\begin{abstract}
Background: Although tracheal stenosis occurs in relapsing polychondritis (RP), no studies exist that have clarified correlations between quantitative airway measurement and spirometry in RP patients. Objectives: The aim of this study was to investigate correlations between the cross-sectional area (CSA) of the trachea and spirometric values in patients with RP. Methods: The institutional review board approved this retrospective study, and written informed consent was waived. Twenty-six patients with RP underwent spirometry and chest computed tomography (CT) at full inspiration and end-expiration. On inspiratory and expiratory chest CT images, CSA at the intrathoracic trachea was measured for all CT slices, and the mean and minimum tracheal CSA were obtained. Correlations between the tracheal CSA and spirometric values were assessed by Spearman's rank correlation analysis. Results: Tracheal CSA measurements for inspiratory and expiratory scans were significantly correlated with
\end{abstract}

(c) 2015 S. Karger AG, Basel

0025-7931/15/0906-0468\$39.50/0
FEV $_{1}$, FEV $_{25-75 \%}$, and peak flow values ( $\rho=0.51-0.86, p<$ 0.01 ). During each inspiratory or expiratory phase, the minimum tracheal CSA achieved a higher correlation coefficient with spirometric values than the mean CSA. Conclusion: Tracheal dimensions for both inspiratory and expiratory CT are significant predictors of pulmonary function in patients with $\mathrm{RP}$. The narrowest tracheal dimension likely determines the severity of airflow limitation in RP.

(c) 2015 S. Karger AG, Basel

\section{Introduction}

Relapsing polychondritis (RP) is a rare systemic inflammatory disease which is characterized by recurrent inflammatory changes in proteoglycan-rich cartilage tissues of the human body [1-5]. Similar to the auricle and nose, the respiratory tract is also affected by RP. It has been reported that respiratory tract complications occur in 50-65\% of RP patients throughout their clinical courses and that the mortality rate from respiratory complications is estimated at $10 \%$ in patients with RP [6-10].

\section{KARGER 125}

E-Mail karger@karger.com www.karger.com/res
Masamichi Mineshita, MD, $\mathrm{PhD}$

Division of Respiratory Medicine, Department of Internal Medicine St. Marianna University School of Medicine

2-16-1 Sugao, Miyamae-Ku, Kawasaki, Kanagawa 216-8511 (Japan)

E-Mail m-mine@marianna-u.ac.jp 
During bronchoscopy or endobronchial ultrasound, RP patients often demonstrate respiratory complications such as inflammation of the tracheobronchial wall, airway stenosis, and dynamic collapse of the proximal airways $[11,12]$. Although these bronchoscopic examinations are useful for observing the location and severity of airway lesions, the procedure is invasive and can increase the risk of aggravating respiratory symptoms and airway stenosis, especially during acute exacerbation or coincidental airway infection. Therefore, a combination of noninvasive examinations such as pulmonary function tests (PFTs) and chest computed tomography (CT) are considered beneficial in monitoring and evaluating airway tract involvement in RP [5-10].

On chest CT or radiography, it has been reported that various abnormal findings can be observed in patients with RP. Typically, airway wall (cartilage) thickening caused by acute inflammation can result in airway narrowing and stenosis in the following chronic phase, which is often accompanied by abnormal calcification [13-17]. Moreover, by using combined inspiratory and expiratory CT scans, abnormal airway collapse (tracheobronchomalacia) and air trapping in the lung field can be visualized [15, 7-19].

Interestingly, although several studies have evaluated these CT abnormalities in RP patients, no previous studies have investigated correlations between CT-based quantitative airway measurement and PFTs in RP patients. Considering that some previous studies have found significant correlations between tracheal dimensions and spirometric values in other diseases [20,21], it can be predicted that there might be an association between airway dimensions and PFTs in RP patients. On conventional chest $\mathrm{CT}$, with two-dimensional axial viewing, measuring tracheal dimensions is much easier and reproducible than measuring the major bronchi or peripheral airways. We therefore targeted the trachea and hypothesized that smaller tracheal dimensions predict worse obstructive conditions on spirometry. Furthermore, if tracheal collapse was associated with disease severity, it would be found that expiratory tracheal dimensions are more correlated with the airflow limitation than inspiratory dimensions, similar to chronic obstructive pulmonary disease [22].

Thus, the aim of this study is two pronged: first, to clarify correlations between the cross-sectional area (CSA) of the trachea and spirometric values in patients with RP, and second, to investigate whether expiratory tracheal CSA is a more reliable predictor than inspiratory CSA.

CT Measurements in RP
Table 1. Clinical characteristics of the 26 subjects

\begin{tabular}{lcc}
\hline & Mean \pm SD & Range \\
\hline Age, years & $57.7 \pm 13.7$ & $23-80$ \\
Height, cm & $159.6 \pm 9.6$ & $138.5-177.0$ \\
Weight, kg & $54.4 \pm 8.6$ & $28-68$ \\
FVC, 1 & $2.8 \pm 0.9$ & $1.4-5.0$ \\
$\mathrm{FEV}_{1}, 1$ & $1.5 \pm 0.8$ & $0.5-3.2$ \\
$\mathrm{FEV}_{1} / \mathrm{FVC}$ & $0.51 \pm 0.18$ & $0.20-0.78$ \\
$\mathrm{FEV}_{1}, \%$ predicted & $51.6 \pm 18.6$ & $20.3-80.7$ \\
$\mathrm{FEF}_{25-75 \%}, 1 /$ s & $0.96 \pm 0.69$ & $0.26-2.27$ \\
$\mathrm{FEF}_{25-75 \%} \%$ predicted & $30.7 \pm 23.0$ & $7.5-103.4$ \\
$\mathrm{PEF}, 1 / \mathrm{s}$ & $3.5 \pm 2.3$ & $0.9-9.1$ \\
$\mathrm{PEF}_{\%} \%$ predicted & $50.4 \pm 33.2$ & $17.0-134.2$ \\
\hline
\end{tabular}

\section{Materials and Methods}

This retrospective study was approved by the institutional review board at St. Marianna University School of Medicine, which waived the need for informed consent. CT images and spirometric data for part of this study population were analyzed for a different purpose in a previous study, which did not include airway dimension data [17].

\section{Subjects}

We reviewed medical records and previous chest CT images of patients at our institution between April 2008 and April 2014. Thirty-nine consecutive patients with RP who underwent chest CT were identified. All patients were clinically diagnosed with RP according to current diagnostic criteria. The diagnosis of RP was based on the presence of three or more clinical signs, one clinical sign in addition to histological confirmation, or involvement of two or more sites with a favorable response to treatment based on the criteria by McAdam et al. [1] or by Damiani and Levine [2].

Exclusion criteria for the study subjects were as follows: a history of tracheotomy $(\mathrm{n}=10)$, under-aged patients $(<18$ years old; $\mathrm{n}=2)$, and no PFTs within 2 weeks of chest CT $(\mathrm{n}=1)$. Thus, 26 patients (12 males and 14 females; mean age, 57.7 years; age range, 23-80 years) were included in this study. Patient characteristics are summarized in table 1 . Among the 26 patients, 13 (50\%) were current or previous smokers (current smokers, 4; previous smokers, 9; smoking index, 23.3 pack-years). The remaining 13 patients did not have a smoking history.

\section{Computed Tomography}

Patients were scanned with a 64- or 80-row detector CT scanner (Aquilion 64 or Aquilion PRIME, Toshiba Medical Systems, Otawara, Japan). Chest CT was performed in the supine position during a breath hold at full inspiration and end-expiration. $\mathrm{Pa}$ tients were instructed how to hold their breaths before scanning by the performing technician. The scanning parameters for CT scans were as follows: collimation, $0.5 \mathrm{~mm}$; tube voltage, $120 \mathrm{kVp}$; gantry rotation time, $0.5 \mathrm{~s}$; beam pitch, 0.828 (Aquilion 64) or 0.813 (Aquilion PRIME). The tube current setting for the Aquilion 64 scanner $(\mathrm{n}=24)$ was as follows: $200 \mathrm{~mA}$ for inspiratory scans and $80 \mathrm{~mA}$ for expiratory scans $(\mathrm{n}=17)$; fixed $200 \mathrm{~mA}$ for both 
Table 2. Tracheal CSAs and correlations with spirometric values

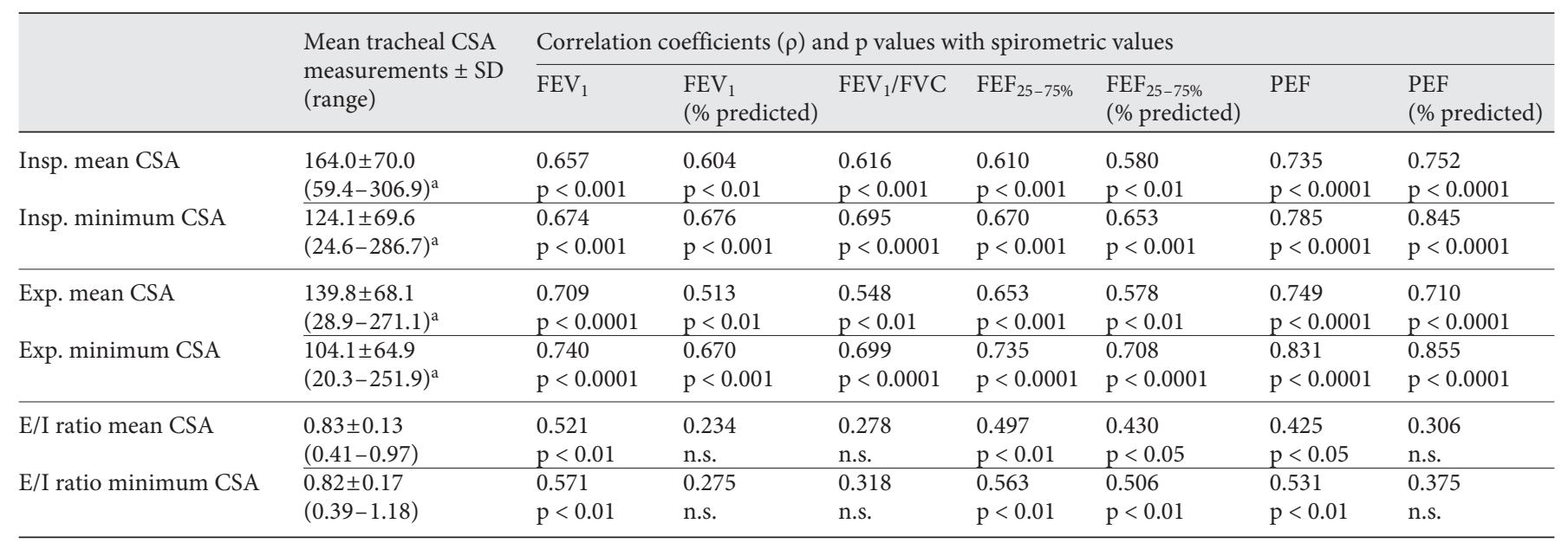

Insp. = Inspiratory; Exp. = expiratory; n.s. $=$ not significant. ${ }^{a}$ Measured in $\mathrm{mm}^{2}$.

inspiratory and expiratory scans $(\mathrm{n}=5)$; fixed 250 or $300 \mathrm{~mA}$ for both inspiratory and expiratory scans $(n=2)$. The tube current setting for the Aquilion PRIME scanner was varied by automatic exposure control. All images were reconstructed using a standard algorithm (FC04) with a slice thickness of $5 \mathrm{~mm}$. The field of view was $32 \mathrm{~cm}$, and the pixel size was $0.625 \times 0.625 \mathrm{~mm}$.

\section{CSA Measurement of the Trachea}

Tracheal CSA measurements in this study followed the methods of a previous study using an open-source image-processing program (Image J, version 1.48, http://imagej.nih.gov/ij/) [20]. First, all axial CT images including the intrathoracic trachea (from the top of the apex to the carina) were selected from each series of inspiratory and expiratory CT scans (from 9 to 11 images based on the patient's body habitus). Second, on each image, the tracheal lumen was extracted from the surrounding structures using a semiautomatic threshold technique (between -500 and $-1,024$ Hounsfield units). Finally, the extracted tracheal lumen was measured as the tracheal CSA on the selected images, and the mean and minimum tracheal CSAs were obtained. Collapsibility of the trachea was also calculated by the expiratory/inspiratory (E/I) ratios of these CSA indices.

\section{Pulmonary Function Tests}

All 26 subjects underwent spirometry within 2 weeks of obtaining CT scans. Spirometry measurements included: forced vital capacity (FVC), forced expiratory volume in one second $\left(\mathrm{FEV}_{1}\right)$, forced expiratory flow of mid-expiratory phase $\left(\mathrm{FEF}_{25-75 \%}\right)$, and peak flow (PEF). The ratio of $\mathrm{FEV}_{1}$ to $\mathrm{FVC}$ was calculated $\left(\mathrm{FEV}_{1} /\right.$ $\mathrm{FVC}$ ). Values for $\mathrm{FEV}_{1}, \mathrm{FEF}_{25-75 \%}$, and PEF were also expressed as percentages of predicted values. The results of the spirometry are summarized in table 1 .

\section{Statistical Analysis}

Correlations between tracheal CSA indices and spirometric values were evaluated using Spearman's rank correlation analysis. All statistical analyses were performed using JMP 9.0 software
(SAS Institute, Cary, N.C., USA). Continuous data were expressed as means \pm standard deviations (SD). For all statistical analyses, a $\mathrm{p}$ value $<0.05$ was considered statistically significant.

\section{Results}

CSA measurements of the trachea and their correlations with spirometric values are shown in table 2. From inspiratory to expiratory scans, the mean CSA decreased from 164.0 to $139.8 \mathrm{~mm}^{2}$, whereas the minimum CSA decreased from 124.1 to $104.1 \mathrm{~mm}^{2}$. On both inspiratory and expiratory scans, the mean and minimum tracheal CSA significantly and positively correlated with all spirometric values ( $p=0.01$ ), suggesting that tracheal luminal narrowing is a significant predictor of airflow limitation. Furthermore, the minimum tracheal CSA achieved higher correlation coefficients than the mean tracheal CSA on inspiratory or expiratory scans. Except for $\mathrm{FEV}_{1} \%$ predicted values that were most strongly correlated with the inspiratory minimum tracheal CSA, all other spirometric values were most strongly correlated with the expiratory minimum CSA $\left(\mathrm{FEV}_{1}, \rho=0.740, \mathrm{p}<0.0001 ; \mathrm{FEV}_{1} / \mathrm{FVC}\right.$, $\rho=0.699, \mathrm{p}<0.0001 ; \mathrm{FEF}_{25-75 \%}, \rho=0.735, \mathrm{p}<0.0001$; PEF, $\rho=0.831, \mathrm{p}<0.0001$; fig. $1-3$ ).

On the other hand, tracheal collapsibility, which was defined as the E/I ratios of the mean and minimum tracheal CSAs, was mildly or insignificantly correlated with spirometric values (table 2). This suggests that static tracheal dimensions could be more important for airflow limitation than tracheal collapsibility in this study cohort. 
Fig. 1. Correlations between the expiratory minimum tracheal CSA and spirometric values. Significant correlations with all spirometric values are confirmed $\left(\mathbf{a} \mathrm{FEV}_{1}\right.$; b $\mathrm{FEV}_{1} / \mathrm{FVC}$; $\mathrm{FEF}_{25-75 \%}$; d PEF).

Fig. 2. CT images of an RP patient with severe obstructive conditions (63-year-old female, $\mathrm{FEV}_{1} / \mathrm{FVC}=0.29, \mathrm{PEF}=0.93$ liters/s). The tracheal wall is thickened and the luminal area is small. The measured minimum CSA of the trachea was 33.2 $\mathrm{mm}^{2}$ on inspiratory CT and $22.7 \mathrm{~mm}^{2}$ on expiratory CT.

Fig. 3. CT images of an RP patient with mild obstructive conditions (36-year-old male, $\mathrm{FEV}_{1} / \mathrm{FVC}=0.64, \mathrm{PEF}=8.54$ liters $/ \mathrm{s}$ ). Tracheal wall thickening is not obvious and the luminal area is larger than in the patient shown in figure 2 . The measured minimum tracheal CSA was $286.7 \mathrm{~mm}^{2}$ at inspiration and $251.9 \mathrm{~mm}^{2}$ at expiration.
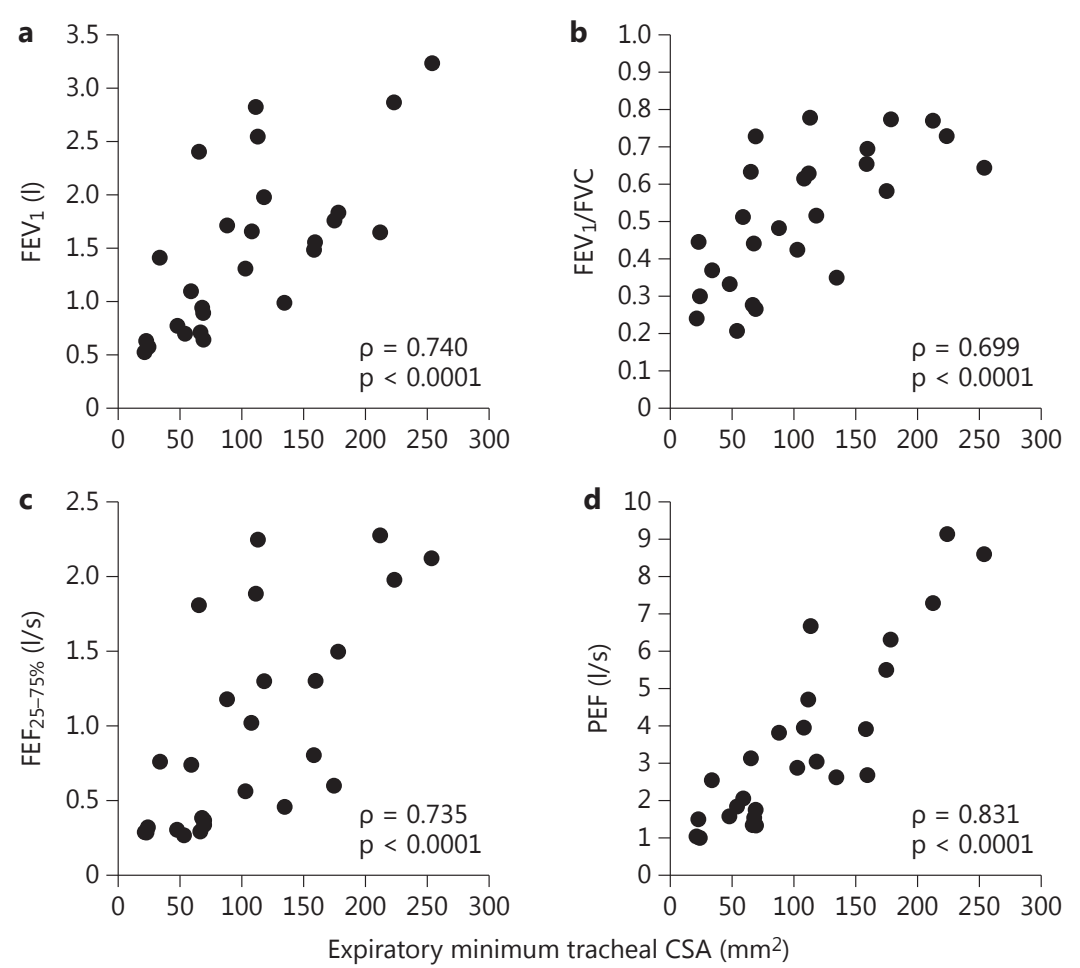

Expiratory minimum tracheal CSA $\left(\mathrm{mm}^{2}\right)$
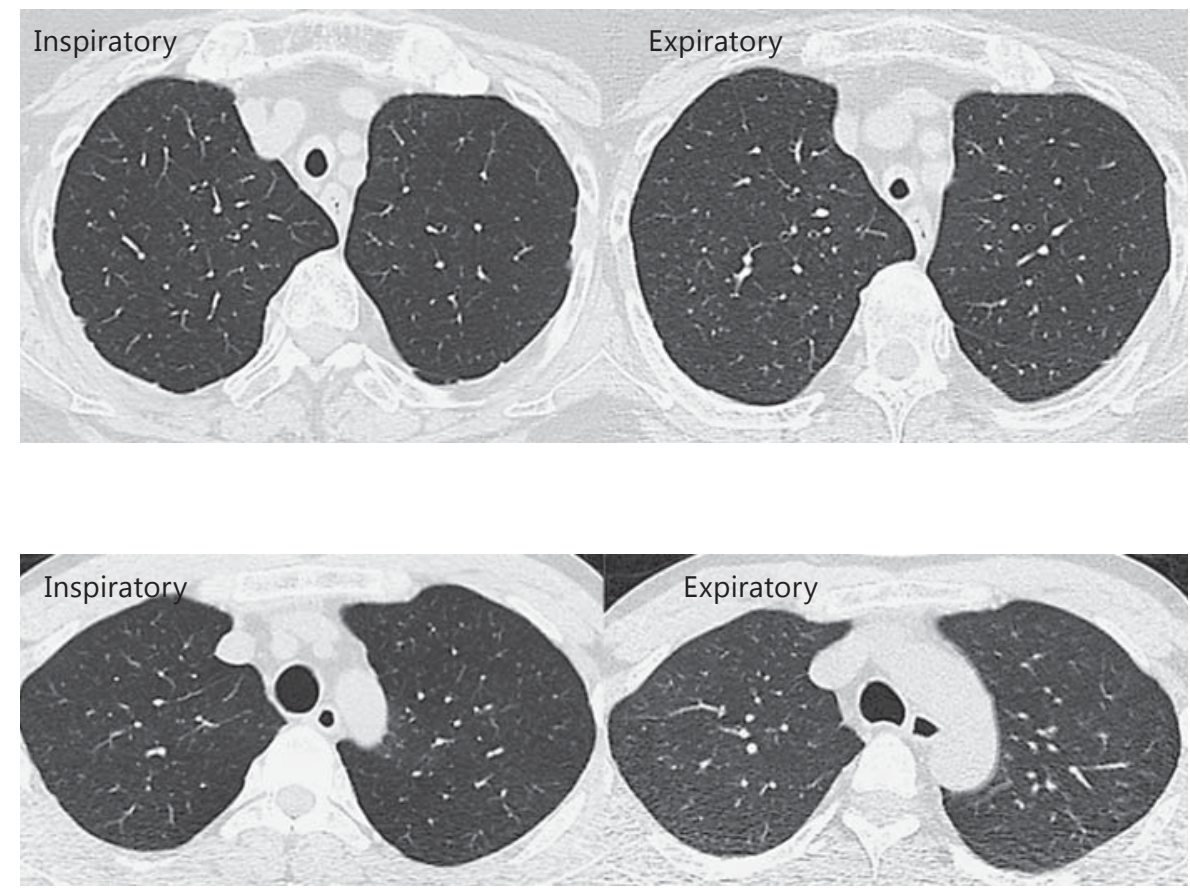


\section{Discussion}

In this study, we demonstrated that tracheal CSAs on inspiratory and expiratory CT scans significantly correlated with spirometric values in RP patients. Furthermore, the minimum tracheal CSA on expiratory CT was found to be the strongest predictor of lung function, which can be used as a new imaging parameter to monitor disease severity for the clinical care of RP. To the best of knowledge, this study is the first to demonstrate the significant correlations between quantitative airway indices and PFTs in patients with RP. On the other hand, tracheal collapsibility between inspiratory and expiratory scans does not always correlate with the spirometric values, which suggests the difficulty in understanding the meaning of tracheal collapse in RP patients.

Airway tract involvement is one of the most important prognostic factors in patients with RP [6-12]. This is caused by recurrent inflammation and the destruction of cartilaginous structures in the airway tree, which leads to airway stenosis, abnormal collapse, and repeated respiratory infections. In general, the mechanisms of airway involvement include the following three steps: first, inflammatory swelling that causes airway narrowing in the active stage; second, the progressive destruction of the tracheal and bronchial cartilage that causes dynamic collapse of the airway in the earlier stage, and third, the formation of fibrous tissue leading to cicatricial contraction in the later stage [3]. These airway involvements can cause dyspnea, asphyxia, and even sudden death by airway obstruction, which is a major cause of death associated with RP. Thus, providing continuous assessment and management of airway lesions is very important for the prognosis of RP. In general, RP patients are monitored by repeated PFTs, which reveal multiple abnormalities including a decrease in PEF or $\mathrm{FEV}_{1}$ on flow volume curves. These spirometric values are very useful in evaluating the activity and severity of airway disease in RP $[9,10]$. However, since spirometry depends much on the patient's effort, the reproducibility and reliability of these examinations are sometimes limited, particularly in children, elder patients, or patients with tracheostomy. Moreover, spirometric results may be affected by other coexisting obstructive diseases, such as chronic obstructive pulmonary disease or bronchial asthma, which cannot be clearly distinguished by spirometry alone in RP patients. In such cases, chest CT can play an important role as an objective examination in the evaluation of airway involvement and coexisting pulmonary diseases. Although radiation exposure and the relatively high cost of chest $\mathrm{CT}$ should be taken into consideration, we believe that chest CT combined with conventional PFTs should be recommended based on the results of this study that significant correlations were observed between tracheal stenosis and spirometric values.

Close correlations between CT-based tracheal CSAs and spirometric values suggest that chest CT can be applied in different stages and conditions of RP. For example, although we excluded patients with tracheotomy due to unreliable spirometric values, monitoring a stenosis at the trachea and proximal bronchi by chest CT is feasible for RP patients with tracheotomy, which can be used as an alternative examination to spirometry. This can also be expanded to early detection in the progression of the most stenotic point, which should be treated by a more invasive method, such as the insertion of a silicon T-tube, stent placement, or surgical airway reconstruction [23-27]. Furthermore, CT-based airway measurements could be beneficial to screen early-stage and stable patients. Considering that airway manifestations are present in approximately $50 \%$ or more of the patients with RP, chest CT may demonstrate slight or mild airway stenosis even in asymptomatic and earlierstage patients. By combining chest CT and spirometry, a more reliable and accurate diagnosis could be achieved for the early detection of recurrence of airway involvement in patients with RP. Similar to the recent report that fluorodeoxyglucose position-emission tomography was useful for diagnosing RP $[28,29]$, a functional evaluation using various radiological modalities may be focused on in future studies of RP.

The present study has several limitations that should be noted. First, the number of patients was relatively small. Since RP is a rare disease, the observations of this study should be reproduced by further studies, such as a multicenter study with a higher number of RP patients. Second, the evaluation of PFTs may not have been sufficient since only spirometry was performed in this study. Lung volume parameters, including functional residual capacity, residual volume, or total lung capacity, could have been evaluated for a better understanding of air trapping or hyperinflation in RP patients. Third, CT scanners and protocols were not standardized. However, since we evaluated tracheal dimensions only, the influence of the unstandardized scan data on tracheal measurements would be minimal compared with CTbased lung assessment. Finally, since we did not adopt dynamic expiratory CT, true tracheal collapsibility during forced expiration was not evaluated in this study. 
In conclusion, the tracheal CSA measured on chest CT closely correlates with the spirometric values, which can be used as clinical predictors of lung function in patients with RP. The smallest tracheal dimension, particularly on expiratory CT scans, is strongly associated with the severity of airflow limitation in RP.

\section{Acknowledgements}

The authors thank Dr. Teppei Inoue and Dr. Shoichiro Matsushita (St. Marianna University School of Medicine) for their support in collecting clinical data. The authors thank Mr. Jason Tonge for his assistance in manuscript preparation.

\section{Financial Disclosure and Conflicts of Interest}

All authors do not have any conflicts of interest to disclose.

\section{References}

1 McAdam LP, O’Hanlan MA, Bluestone R, Pearson CM: Relapsing polychondritis: prospective study of 23 patients and a review of the literature. Medicine 1976;55:193-215.

-2 Damiani JM, Levine HL: Relapsing polychondritis: report of ten cases. Laryngoscope 1979; 89(6 Pt 1):929-946.

-3 Sarodia BD, Dasgupta A, Mehta AC: Management of airway manifestations of relapsing polychondritis: case reports and review of literature. Chest 1999;116:1669-1675.

-4 Michet CJ Jr, McKenna CH, Luthra HS, O'Fallon WM: Relapsing polychondritis: survival and predictive role of early disease manifestations. Ann Intern Med 1986;104:74-78.

5 Sharma A, Gnanapandithan K, Sharma K, Sharma S: Relapsing polychondritis: a review. Clin Rheumatol 2013;32:1575-1583.

6 6 Segel MJ, Godfrey S, Berkman N: Relapsing polychondritis: reversible airway obstruction is not always asthma. Mayo Clin Proc 2004; 79:407-409.

-7 Ernst A, Rafeq S, Boiselle P, Sung A, Reddy C, Michaud G, Majid A, Herth FJ, Trentham D: Relapsing polychondritis and airway involvement. Chest 2009;135:1024-1030.

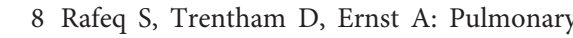
manifestations of relapsing polychondritis. Clin Chest Med 2010;31:513-518.

-9 Mohsenifar Z, Tashkin DP, Carson SA, Bellamy PE: Pulmonary function in patients with relapsing polychondritis. Chest 1982;81:711717.

10 Krell WS, Staats BA, Hyatt RE: Pulmonary function in relapsing polychondritis. Am Rev Respir Dis 1986; 133:1120-1123.

11 Maimon N, Lee P, Paul N, Hwang D, Marras TK, Keshavjee S, Chan CK: Tracheobronchial involvement as a sole manifestation of relapsing polychondritis. J Bronchology Interv Pulmonol 2010;17:5-10.

12 Tillie-Leblond I, Wallaert B, Leblond D, Salez F, Perez T, Remy-Jardin M, Vanhille P, Brouillard M, Marquette C, Tonnel AB: Re- spiratory involvement in relapsing polychondritis. Clinical, functional, endoscopic, and radiographic evaluations. Medicine 1998;77: 168-176.

13 Port JL, Khan A, Barbu RR: Computed tomography of relapsing polychondritis. Comput Med Imaging Graph 1993;17:119-123.

14 Behar JV, Choi YW, Hartman TA, Allen NB, McAdams HP: Relapsing polychondritis affecting the lower respiratory tract. Am J Roentgenol 2002;178:173-177.

15 Lee KS, Ernst A, Trentham DE, Lunn W, Feller-Kopman DJ, Boiselle PM: Relapsing polychondritis: prevalence of expiratory CT airway abnormalities. Radiology 2006;240:565573.

16 Lin ZQ, Xu JR, Chen JJ, Hua XL, Zhang KB, Guan YJ: Pulmonary CT findings in relapsing polychondritis. Acta Radiol 2010;51:522-526.

17 Matsushita S, Matsuoka S, Yamashiro T, Fujikawa A, Kurihara Y, Yagihashi K, Handa H, Miyazawa T, Nakajima Y: Quantitative computed tomography assessment of air trapping in relapsing polychondritis: correlations with spirometric values. J Comput Assist Tomogr 2014;38:968-971.

18 Lee KS, Sun MR, Ernst A, Feller-Kopman D, Majid A, Boiselle PM: Comparison of dynamic expiratory CT with bronchoscopy for diagnosing airway malacia: a pilot evaluation. Chest 2007;131:758-764.

19 Gilkeson RC, Ciancibello LM, Hejal RB, Montenegro HD, Lange P: Tracheobronchomalacia: dynamic airway evaluation with multidetector CT. Am J Roentgenol 2001;176: 205-210.

20 Yamashiro T, San Jose Estepar R, Matsuoka S, Bartholmai BJ, Ross JC, Diaz A, Murayama S, Silverman EK, Hatabu H, Washko GR: Intrathoracic tracheal volume and collapsibility on inspiratory and end-expiratory CT scans correlations with lung volume and pulmonary function in 85 smokers. Acad Radiol 2011;18: 299-305.
21 Ederle JR, Heussel CP, Hast J, Fischer B, Van Beek EJ, Ley S, Thelen M, Kauczor HU: Evaluation of changes in central airway dimensions, lung area and mean lung density at paired inspiratory/expiratory high-resolution computed tomography. Eur Radiol 2003;13: 2454-2461.

22 Matsuoka S, Kurihara Y, Yagihashi K, Hoshino $M$, Nakajima Y: Airway dimensions at inspiratory and expiratory multisection CT in chronic obstructive pulmonary disease: correlation with airflow limitation. Radiology 2008;248:1042-1049.

23 Dunne JA, Sabanathan S: Use of metallic stents in relapsing polychondritis. Chest 1994; 105:864-867.

24 Miyazawa T, Nishine H, Inoue T, Mineshita M, Hiramoto T: Migration of the choke point in relapsing polychondritis during stenting. Am J Respir Crit Care Med 2009;A5778 (abstract).

25 Nakayama T, Horinouchi H, Asakura K, Ohtsuka T, Izumi Y, Kohno M, Nomori H: Tracheal stenosis due to relapsing polychondritis managed for 16 years with a silicon T-tube covering the entire trachea. Ann Thorac Surg 2011;92:1126-1128.

26 Eng J, Sabanathan S: Airway complications in relapsing polychondritis. Ann Thorac Surg 1991;51:686-962.

-27 Karaman E, Duman C, Cansz H, Ylmaz M, Ibrahimov M: Laryngotracheal reconstruction at relapsing polychondritis. J Craniofac Surg 2010;21:211-212.

28 Lei W, Zeng DX, Chen T, Jiang JH, Wang CG, Zhu YH, Huang JA: FDG PET-CT combined with TBNA for the diagnosis of atypical relapsing polychondritis: report of 2 cases and a literature review. J Thorac Dis 2014;6:12851292.

29 Sato M, Hiyama T, Abe T, Ito Y, Yamaguchi S, Uchiumi K, Hashimoto I, Kaburagi T: F-18 FDG PET/CT in relapsing polychondritis. Ann Nucl Med 2010;24:687-690. 